\title{
Impact of Protocol of Nursing Intervention on Sexual Dysfunction among Women with Cervical Cancer
}

\section{Hagar kamal masaud ${ }^{1}$, Ragaa Ali Mohammed Abd Rabo ${ }^{2}$, Soad Abd El Salam Ramadan $^{3}$ and Hanan Elzeblawy Hassan ${ }^{4}$}

(1)Assistant lecturer in Maternity \&Neonatal Nursing, Faculty of Nursing -Beni -suef University, (2) Professor of Maternity \&Neonatal Nursing Faculty of Nursing-Cairo University, (3)Professor of Obstetrics and Women Health Nursing department Faculty of Nursing -Benha University, (4) Assistant professor of Maternal and Newborn Health Nursing department Faculty of Nursing - Beni -suef University

\section{Abstract}

Background: Cervical cancer affects all aspects of a patient's life, including sexual functioning and intimacy. Sexuality is one of the indicators of quality of life; it influences thoughts, feelings, actions, social integration, and therefore, physical and mental health. The present study aimed to evaluate the impact of protocol of nursing intervention on sexual dysfunction among women with cervical cancer. An intervention study design was conducted in out-patient clinic in the oncology unit at Beni-suef university Hospital. A purposive sample of 70 women was included in the study. A quasi-experimental (prepost) study design was used. Data was collected through four types of tools structured interviewing questionnaire sheet, female sexual function index, female sexual distress scale and body image scale. In addition to Supportive material (educational booklet) was given to women. Results: There were high statistical significant differences in the women's total score of knowledge about cervical cancer, total scores of female sexual function index, female sexual distress scale and body image scale at post intervention in which the women had higher score at post intervention $\mathrm{p}(<0.001)$. Conclusion: Educational booklet proved to have a positive effect on knowledge and sexual function of women with cervical cancer. Recommendations: Multidisciplinary collaboration approach for addressing sexual problems related to cervical cancer, preparing health classes for cervical cancer women regarding sexual dysfunction with cervical cancer and further research about nurse's perception and practices regarding sexual dysfunction with cervical cancer.

Key words: Cervical cancer, sexual dysfunction, Protocol of nursing intervention.

\section{Introduction}

Cancer is increasingly growing as a major public health problem in both developed and developing countries. Cancer can impose health, heavy economic and social burden. It is a 
global pandemic affecting both developed and developing regions, but it is rapidly increasing in low and middleincome countries, where resources for prevention, diagnosis and treatment are limited or non-existent (Habtu, Yohannes, Laelago, 2017)

Cervical Cancer (CC) is a health problem due to the high prevalence rates and mortality in women of low socioeconomical levels and in the productive phase of their lives. There is a strong association of this type of cancer with precarious living conditions, low indices of human development, the absence or weakness of community education strategies and with the difficulty of access to public health services for the early diagnosis and treatment (Boyle, Levin, 2014).

Cervical cancer occurs when the cells of the cervix grow abnormally and invade other tissues and organs of the body. When it is invasive, this cancer affects the deeper tissues of the cervix and may have spread to other parts of the body (metastasis), most notably the lungs, liver, bladder, vagina, and rectum . Because of the slowgrowing of cervical cancer and progression through precancerous changes provides opportunities for prevention, early detection, and treatment (Martin, 2018).
Receiving any cancer diagnosis is an unpleasant experience, accompanied by distress, which impacts a person's personal and family life (Soleimani, et al., 2017). As a result of diagnosis, patients experience socio-economic problems, marital issues, and psychological problems. Intense psychological distress is common not only upon receiving a diagnosis, but also throughout treatment. (Brunault, et al. 2016).

Human papillomavirus (HPV) infection is known as one of the steps of the carcinogenesis process. The infection is more frequent among women in the years following the first sexual intercourse. Precursor lesions can occur as a consequence of persistent infection in a process that lasts for 5 to 10 years. (Cândido,et al.,2017).

There are different types of treatment options for patients with cervical cancer. Five types of standard treatment are used: surgery, radiation therapy, chemotherapy, targeted therapy, and immunotherapy. New types of treatment are being tested in clinical trials. Treatment for cervical cancer may cause side effects. Patients may want to think about taking part in a clinical trial (Conrad \& Shiel, 2018) 
There is a tendency of reduction or stability in cervical cancer mortality rate and an increase of the number of women living with the healing or chronicity of the disease. However, the increasing survival, an achievement for the oncology area caused by progress in treatment, is permeated by these treatment consequences, which persist for years. The effects of therapies and the disease adversely affect the quality of life and sexual function of cervical cancer surviving patients. The various therapeutic modalities interfere with the functioning of the pelvic organs, causing sexual, urinary and intestinal dysfunction (Araujo, Janaina, Laurentino,Vieira, 2016).

Sexual dysfunction is one of the most distressful symptoms among cervical cancer survivors. Cancer treatment including radiotherapy results in a high degree of vaginal morbidity and persistent sexual dysfunction. The vaginal symptoms reported after cervical cancer treatment, include sore membranes, reduced lubrication and genital swelling which severely affect the women's sexual health (Hofsjo, et al., 2018)

Nurse is an important member of the health care team to counsel the women in the sensitive and highly charged area of human sexuality. Sexuality and sexual health problems are challenging areas for nurses so should be approached in a way that respects women confidentiality and sensitively explores women needs. (Evans, 2013) Nursing interventions (Education and counseling on sexuality) are used to assist women to resolve their sexual problems. (Chow, Chan, Choi, and Chan 2016)

Education and counseling on sexuality are nursing interventions used to assist patients to resolve their sexual problems. In nurse-led counseling, a nurse provides information and assists patients in making and executing a decision; the nurse also guides the cervical cancer survivor to regain selfconfidence and adapt to physical and psychological changes to optimize survivor autonomy. Nurse-led psychosexual counseling can significantly improve sexual function in patients with gynecological cancer. Education and counseling for women after cancer treatment may also reduce sexual problems and improve marital relationship (Soleimani et al., 2017)

\section{Significance of the problem;}

Cervical cancer is the fourth most frequent cancer in women with an estimated 570,000 new cases in 2018 representing $6.6 \%$ of all female cancers. Approximately $90 \%$ of deaths from cervical cancer occurred in low- and middle-income countries (WHO, 2018) 
Egypt has a population of 30.55 million women ages 15 years and older who are at risk of developing cervical cancer. Current estimates indicate that every year 969 women are diagnosed with cervical cancer and 631 die from the disease. Cervical cancer ranks as the 14th most frequent cancer among women in Egypt and the 14th most frequent cancer among women between 15 and 44 years of age (ICO/IARC Information Centre on HPV and Cancer, 2018) .Sexual oncology is gaining appreciation as a major area needing attention in nursing practice and research. Oncology nurses need to possess a high level of sensibility in dealing with women's sexual health needs. However, sexual health care still inadequate addressed due to barriers such as incorrect assumptions and beliefs toward sexual issues. One of the main roles of oncology nurses is to assess problems in this area to be able to provide anticipatory guidance related to treatment and the resumption of sexual activity, but this is one aspect of care that has been largely ignored by health care providers. Sexuality issues have not been adequately addressed by health care providers.

\section{Aim of the Study}

The aim of this study was to examine the impact of protocol of nursing intervention on sexual dysfunction among women with cervical cancer through:

\section{Hypothesis}

Women with cervical cancer that adopt the protocol of nursing intervention will experience improvement in sexual function compared to before the application of nursing protocol.

\section{Subject and methods}

\section{Research design:}

The study followed a quasiexperimental (pre-post) test study design.

\section{Setting:}

The study was conducted in out-patient clinic in the oncology unit at Beni-suef university hospital.

\section{Sample type:}

A Purposive sample was used.

\section{Sample size:}

Inclusion criteria: All married women that were diagnosed with cervical cancer undergoing different types of treatment; with any cervical cancer degree in all ages was recruited.

Exclusion criteria: Gynecological tumor, e.g. vaginal, breast and uterine cancer was excluded.

\section{Sample Size;}

Steven and Thompson equation was used to calculate the sample size from the next formula; 


$$
n=\frac{N p(1-p)}{(N-1)\left(d^{2} / z^{2}\right)+p(1-p)}
$$

$\mathrm{N}=$ Population (140)

$\mathrm{Z}=$ confidence level $95 \%$ (1.96)

$\mathrm{P}=$ probability $(10 \%)$

$\mathrm{d}=$ margin of error $(0.05)$

So, sample size $(\mathrm{n})=70$

\section{Tools of data collection:}

Four tools were used for data collection;

Tool I: Structured interviewing

questionnaire sheet was developed by the researcher in the Arabic language based on a review of recent literatures. It was consist of four parts:

1. Socio-demographic characteristics of women as age, level of education, occupation, and residence.

2. Obstetrical \& gynecological history as regards: menstrual history, parity (menopause, secondary amenorrhea).

3. Medical \& surgical history: how cervical cancer was detected, stage of cervical cancer, type of treatment regimen, types of surgery performed.

4. Side effects of cervical cancer treatment such as nausea, vomiting, diarrhea, loss of hair, dyspepsia, pain, bladder irritation, narrowing of the vagina, anemia, and fatigue.

5. Women's knowledge about cervical cancer such as (definition, causes, signs, symptoms, risk factors, methods of prevention, diagnosis, treatment) of cervical cancer.
Scoring system for women's knowledge part of the interviewing questionnaire (Women's knowledge about cervical cancer):

Each answer were scored zero for "incorrect" answers and one for "correct" answers. Scores was summed up and converted to percent. $60 \%$ and more of the total scores considered satisfactory knowledge while less than $60 \%$ considered unsatisfactory knowledge.

Tool II: Female Sexual Function Index (FSFI).A multidimensional self - report questionnaire that assesses the key dimensions of female sexual function during the four weeks prior to the interview day. It comprises 19

Multiple choice questions that measure 6 , domains, including desire domain (2 questions), arousal (4 questions), lubrication (4questions), orgasm (3 questions), satisfaction (3 questions) and sexual pain (3 questions). Each domain scored from 0/1 (no sexual activity or sexual dysfunction, respectively) to 5 (suggestive of normal sexual activity). The domain score determined by adding the score of the questions that comprise the domain and multiply the sum by the domain factor (i.e., desire 0.6, arousal and lubrication 0.3 , orgasm, satisfaction and pain 0.4$)$. While the full-scale score calculated by adding the six domain scores ( $=2$ to 36$)$. For the present study, 
the researchers will use the Arabic version FSFI that was translated by Anis et al (2011). It was validated for the Egyptian population. A total score of 28.1 was taken as the cutoff point for the Arabic version FSFI to distinguish between women with FSD and those with normal function (sensitivity $96.7 \%$, specificity 93.2\%). The scale was translated into Arabic language.

Scoring system for Female Sexual Function Index

The individual domain scores and full scale (overall) score of the FSFI can be derived from the computational formula outlined in the table below. For individual domain scores, add the scores of the individual items that comprise the domain and multiply the sum by the domain factor (see below). Add the six domain scores to obtain the full scale score. It should be noted that within the individual domains, a domain score of zero indicates that the subject reported having no sexual activity during the past month. Subject scores can be entered in the right hand column. A total score of 28.1 was taken as the cutoff point for the Arabic version FSFI to distinguish between women with FSD and those with normal function.

Tool III: Female sexual distress scalerevised for assessing distress in women with hypoactive sexual desire disorder.
This is a self-report questionnaire designed by Derogatis et al. (2008). It consists of 13 items assessing different aspects of sexual activity- related distress in women. All items are scored on a five-point likert -type scale ranging from 0 (never) to 4 (always), with a higher score indicating more sexual distress. The scale was translated into Arabic language.

3- Scoring system for tool Female sexual distress scale

This tool consists of 13 items to assess different aspects of sexual activity-related distress in women. Women were asked to choose the number that defines the frequency of discomfort of the sexual problem she has had in the last 30 days.

\section{Scoring system for Female sexual distress}

All items are scored on a fivepoint Likert scale. Responses ranged from zero (never) to 4 (always), the total scores to be received are between 0 and 52with a higher score indicating more sexual distress; women receiving 11 or higher points was deemed to have sexual disorders.

Tool IV: Body Image Scale. It is a self - report measure of the woman's body image. This 10-item scale was constructed in collaboration with the 
European Organization for Research and Treatment of Cancer (EORTC) designed by (Hopwood et al, 2001). The scale showed a high reliability (Cronbach's alpha 0.93) and good clinical validity. Scores on the body image range from 9 to 36. Good level was 9-17, a considerable level was 18-26 and bad level was 27-36. Lower scores indicate a greater level of body image. The scale was translated into Arabic language.

\section{Scoring system for Body Image Scale}

This tool consists of 10 item measure, developed to briefly and comprehensively assess affective (e.g. feeling self-conscious), behavioral (e.g. difficulty at looking at the naked body) and cognitive (e.g. satisfaction with appearance) dimensions of body image in cancer patients and has been designed to use with any cancer. It uses a 4-point response scale $\left(0 \frac{1}{4}\right.$ not at all to $3 \frac{1}{4}$ very much) and the final score is the sum of the 10 items, ranging from 0 to 30, with zero scores representing no symptom or distress and higher scores corresponding to increasing symptoms and distress or more body image concerns.

-Supportive material: Educational booklet was designed by the researcher based on review of literatures containing data regarding the following;

- Cervical cancer causes, degrees, treatment and management of treatment side effects e.g (nausea, vomiting, diarrhea, dyspnea, gingivitis) various physical, psychological, sexual, and reproductive problems.

-Physical activity including walking for at least 30 minutes / day .Also, performing body range of motion exercise, relaxation techniques including breathing exercise, distraction and recreation.

-Diet therapy (high fiber diet, low-fat diet, high vegetables/fruits diet).

-Information and education on

reproductive organs and sexual function, including anatomy and physiology of female genital system, explanation in the series of female sexual response cycle.

-Types of sexual dysfunctions, dealing with sexuality problems, numerous relaxation and other exercises for improving sexual fitness (such as Kegel exercise, sensation focus exercise, and exercise of various technical positions during sexual intercourse).

\section{Validity of the tools:}

Content validity was done through five experts from Faculty Members of Maternal Health Nursing department and obstetrics medicine Specialty to ascertain relevance and completeness.

\section{Ethical considerations;}

Informed oral consent was obtained from women after explaining the purposes of the study, no harmful methodology was used, each woman had the right to withdraw from the study at 
any time, confidentiality was maintained and human rights were used.

\section{Pilot study:}

A pilot study was conducted on $10 \%$ (7women) to evaluate the applicability, efficiency, clarity of tools, assessment of feasibility of field work and identification of suitable place for interviewing women, beside to detect any possible obstacles that might face the researcher and interfere with data collection. Necessary modifications were done based on the pilot study findings such as (omission of some questions from tool) in order to strengthen their contents or for more simplicity and clarity the pilot sample was excluded from the main study sample.

\section{Data collection phases:}

- The data was collected through a period of six months from the start of August 2019 till the end of January2020.

- The researcher attended at the previous mentioned setting till all the prementioned sample size collected. The researcher introduced herself to women and explains the aim of the study prior to data collection. The sample was collected 2days per week from 9am to $2 \mathrm{pm}$.the approval of women was obtained orally before data collection.
-The researcher filled the interviewing questionnaire from the women. Filling questionnaire ranged from 15 to20 minutes from the women. The sexual nursing counseling was given by the researcher at the outpatient unit in three meeting sessions.

-Weekly follow up by using telephone call for instruction \& reinforcement about items of sexual counseling. The effect of sexual nursing intervention was evaluated through comparing between the women's condition (dysfunction, sexual distress and body image) pre and post-intervention after1 month.

\section{Statistics analysis:}

The collected data was revised, coded, tabulated and introduced to a PC using statistical package for social sciences (IBM SPSS .25.0). Data was presented and suitable analysis was done according to the type of data obtained for each parameter. Descriptive Statistics: Mean, Standard deviation (SD) and range for parametric numerical data. Frequency and percentage of nonnumerical data. Cronbach alpha and Spearman-Brown coefficients were calculated to assess the reliability of the tools. 


\section{Results}

Table (1) reveals that approximately slightly less than one quarter $(21.4 \%)$ of the study sample their age ranged from $(30:<40)$ years old and more than half $(51.4 \%)$ their age more than (50) years old with mean age of (49.4 \pm 9.38$)$. Regarding educational level of women slightly less than half (48.6\%) had secondary education. Regarding occupation more than half $(64.3 \%)$ of women were house wives. Regarding educational level of the spouse slightly less than one third (30\%) had basic education. Regarding residence more than half $(52.8 \%)$ of women was from urban areas and the mean marriage age of women was (19.1).

Table (2) shows that only (4.3\%) of women had satisfactory knowledge during pre-intervention and approximately all of them $(95.7 \%)$ had satisfactory knowledge at post intervention, there was high statistical significant improvement in the women's total knowledge regarding to cervical cancer.

Figure (1): displays that the majority of women had satisfactory total knowledge regarding cervical cancer post intervention

Table (3) illustrates that no women had sexual functioning at pre-intervention while changed to $50 \%$ at postintervention. Highly statistical significant difference is observed in the total scores of FSFI among studied sample at pre and post intervention.

Figure (2): displays that all women had no sexual function index pre intervention while this percentage decreased to $50 \%$ post intervention

Table (4) reveals that more than three quarters $(88.6 \%)$ of the studied women had sexual distress at pre-intervention and all $(100 \%)$ of them had no sexual distress at post-intervention. Highly statistical significant difference is observed among women in the total scores of the sexual distress scale.

Figure (3) reveals that more than three quarters of women had total sexual distress pre intervention. However, post intervention all women had no total sexual distress

Table (5) indicates that more than three quarters $(90 \%)$ of the studied women had body image distress at pre intervention while nearly all $(97.1 \%)$ of them had good body image at post intervention. Highly statistical significant difference is observed among women in the total scores of the body image scale.

Figure (4) reveals that nearly all women had good total body image post intervention

Table (6) reveals that there was correlation between total knowledge scores of women and their total body image scores and there was no correlation between total knowledge scores of women and their total sexual distress scores. 
Impact of Protocol of Nursing Intervention on Sexual Dysfunction among Women with

Cervical Cancer

Table (1): Distribution of demographic characteristics of the study subjects $(\mathbf{n}=\mathbf{7 0})$.

\begin{tabular}{|c|c|c|c|}
\hline \multicolumn{2}{|c|}{ Demographic characteristics } & No & \\
\hline \multirow[t]{4}{*}{ 1. Age } & $30:<40$ years & 15 & 21.4 \\
\hline & $40:<50$ years & 19 & 27.1 \\
\hline & $>50$ years & 36 & 51.4 \\
\hline & Mean \pm SD & \multicolumn{2}{|c|}{$9.38 \pm 49.4$} \\
\hline \multirow{4}{*}{$\begin{array}{l}\text { 2. Educational } \\
\text { level of women }\end{array}$} & Illiterate & 2 & 2.9 \\
\hline & Basic education & 24 & 34.3 \\
\hline & Secondary education & 34 & 48.6 \\
\hline & High education & 10 & 14.3 \\
\hline \multirow[t]{2}{*}{ 3. Occupation } & Working & 25 & 35.7 \\
\hline & House wife & 45 & 46.3 \\
\hline \multirow{4}{*}{$\begin{array}{l}\text { 4. Educational } \\
\text { level of spouse }\end{array}$} & Illiterate & 8 & 11.4 \\
\hline & Basic education & 21 & 30 \\
\hline & Secondary education & 20 & 28.6 \\
\hline & High education & 21 & 30 \\
\hline \multirow[t]{2}{*}{ 5. Residence } & Rural & 33 & 47.2 \\
\hline & Urban & 37 & 52.8 \\
\hline \multirow[t]{3}{*}{ 6. Marriage age } & $<20$ years & 40 & 57.1 \\
\hline & 20: 30 years & 30 & 42.9 \\
\hline & Mean \pm SD & \multicolumn{2}{|c|}{$4.23 \pm 19.3$} \\
\hline
\end{tabular}

Table (2): Percentage distribution of women's total knowledge regarding cervical cancer $(\mathbf{n}=\mathbf{7 0})$.

\begin{tabular}{|l|c|c|c|c|c|c|}
\hline \multirow{2}{*}{} & \multicolumn{2}{|c|}{ Pre-knowledge } & \multicolumn{2}{|c|}{ Post-knowledge } & \multirow{2}{*}{$\mathbf{X}^{2}$} & \multirow{2}{*}{ P-value } \\
\cline { 2 - 5 } & No. & $\%$ & No. & $\%$ & & \\
\hline $\begin{array}{l}\text { Satisfactory } \\
\text { knowledge }\end{array}$ & 3 & 4.3 & 67 & 95.7 & 27.12 & $.000^{* *}$ \\
\cline { 1 - 5 } $\begin{array}{l}\text { Unsatisfactory } \\
\text { knowledge }\end{array}$ & 67 & 95.7 & 3 & 4.3 & & \\
\hline
\end{tabular}

$(* *)$ highly statistically significant at $\mathrm{P}<0.001$ 


\section{Total Women's Knowledge}

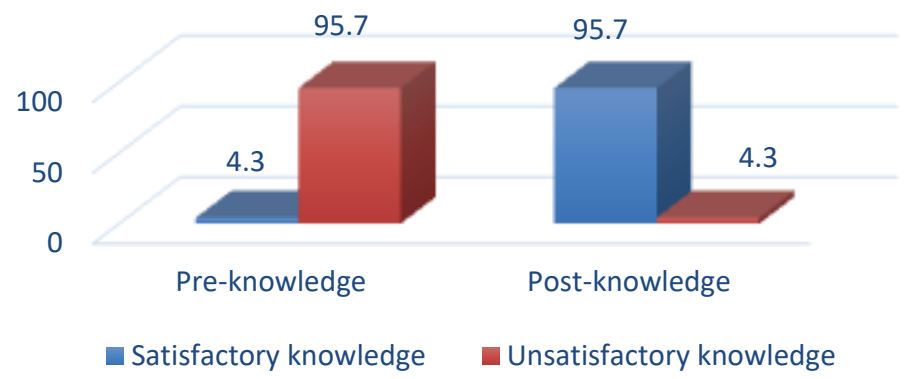

Figure (1): Percentage distribution of women's total knowledge regarding cervical cancer $(\mathbf{n}=\mathbf{7 0})$.

Table (3): Percentage distribution of women's total female sexual functions index indicators $(n=70)$.

\begin{tabular}{|c|c|c|c|c|c|c|}
\hline & \multicolumn{2}{|c|}{ Pre } & \multicolumn{2}{c|}{ Post } & \multirow{2}{*}{$\mathbf{X}^{2}$} & \multirow{2}{*}{ P-value } \\
\cline { 2 - 5 } & No. & \% & No. & \% & & \\
\hline Sexual functioning & 0 & 0 & 35 & 50 & \multirow{2}{*}{19.17} & \multirow{2}{*}{$.000^{* *}$} \\
\cline { 1 - 4 } Sexual dysfunction & 70 & 100 & 35 & 50 & & \\
\cline { 1 - 4 } Mean \pm SD & \multicolumn{2}{|c|}{$33.75 \pm 13.12$} & \multicolumn{2}{|c|}{$55.13 \pm 8.31$} & & \\
\hline
\end{tabular}

$(* *)$ highly statistically significant at $\mathrm{P}<0.001$

\section{Total FSFI}

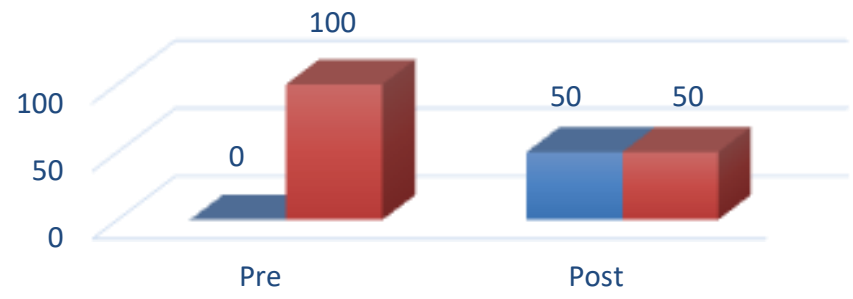

Sexual functioning Sexual dysfunction

Figure (2): Percentage distribution of women's total sexual function index indicators $(\mathbf{n}=\mathbf{7 0})$. 
Impact of Protocol of Nursing Intervention on Sexual Dysfunction among Women with Cervical Cancer

Table (4): Percentage distribution of women's total sexual distress scores $(n=$ 70).

\begin{tabular}{|l|c|c|c|c|c|c|}
\hline & \multicolumn{2}{|c|}{ Pre-intervention } & \multicolumn{2}{|c|}{ Post-intervention } & \multirow{2}{*}{$\mathbf{X}^{2}$} & \multirow{2}{*}{ P-value } \\
\cline { 2 - 5 } & No. & $\%$ & No. & $\%$ & & \\
\hline Sexual distress & 62 & 88.6 & 70 & 0 & 21.46 & \multirow{2}{*}{$.000^{* *}$} \\
\cline { 1 - 5 } No sexual distress & 8 & 11.4 & 0 & 100 & & \\
\hline
\end{tabular}

(**) highly statistically significant at $\mathrm{P}<0.001$

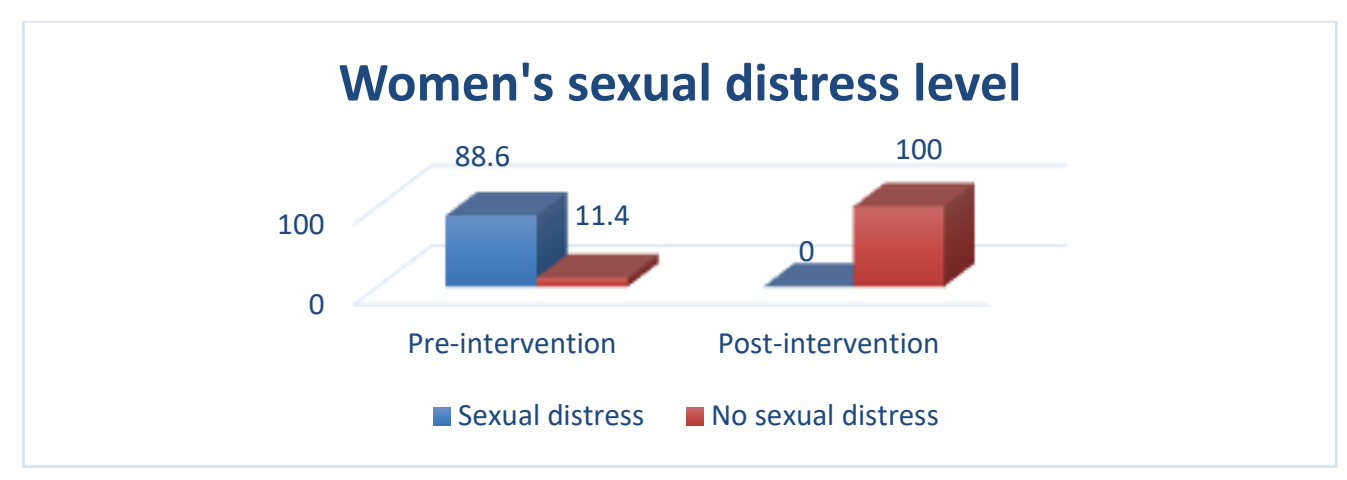

Figure (3): Percentage distribution of women's total sexual distress scores

Table (5): Percentage distribution of women's total body image scores $(n=70)$.

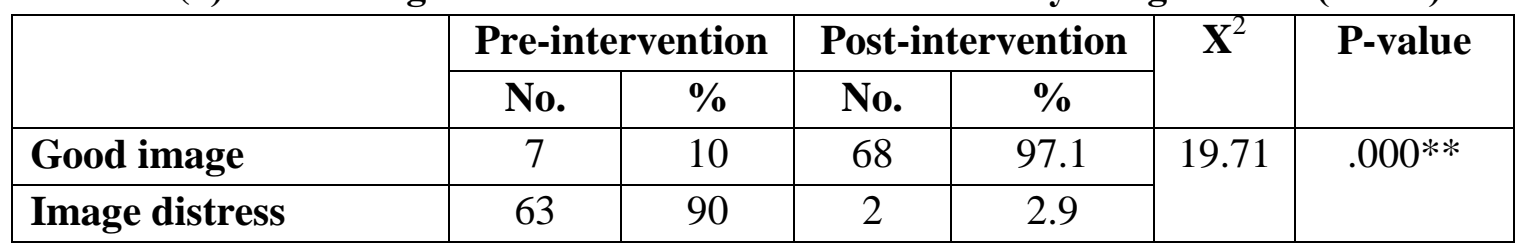

$(* *)$ highly statistically significant at $\mathrm{P}<0.001$

\section{Body Image Total Scores}

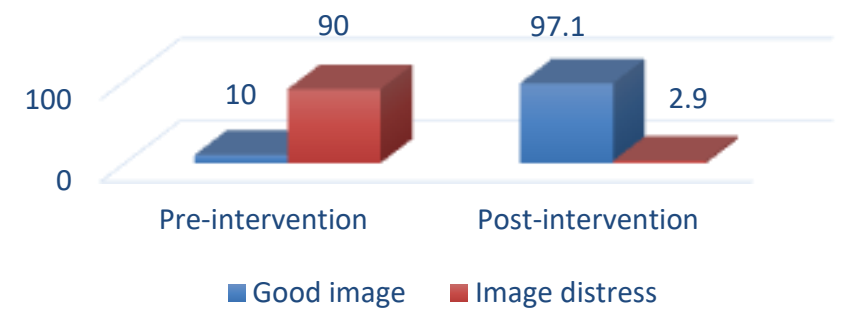

Figure (4): Percentage distribution of women's total body image scores 
Hagar kamal, Ragaa Ali Abd Rab, Soad Abd El Salam Ramadan and Hanan Elzeblawy

Table (6): Correlation matrix of the study variables;

\begin{tabular}{|l|c|c|c|c|}
\hline & & $\begin{array}{c}\text { Total } \\
\text { knowledge }\end{array}$ & $\begin{array}{c}\text { Body image } \\
\text { scores }\end{array}$ & $\begin{array}{c}\text { Sexual } \\
\text { distress scores }\end{array}$ \\
\hline \multirow{2}{*}{ Total knowledge } & $\mathbf{r}$ & 1 & -.252 & -.086 \\
\cline { 2 - 5 } & $\mathbf{p}$ & - & $.035^{*}$ & .481 \\
\hline Body image scores & $\mathbf{r}$ & -.252 & 1 & .123 \\
\cline { 2 - 5 } & $\mathbf{p}$ & $.035^{*}$ & - & .311 \\
\hline Sexual distress scores & $\mathbf{r}$ & -.086 & .123 & 1 \\
\cline { 2 - 5 } & $\mathbf{p}$ & .481 & .311 & - \\
\hline
\end{tabular}

(*) statistically significant $\mathrm{p}<0.05(* *)$ high statistically significant $\mathrm{p}<0.01$

\section{Discussion}

Sexuality is a vital part of the quality of life and overall health. Cancer diagnosis can affect many aspects of women's daily routine, including their sexuality. Many oncology gynecological patients have fright and care about the fact that their marriage will be at risk and their sexual relationships with their partner will be influenced due to sexual problems that are caused by cancer and its treatment. (American Cancer Society, 2020)

In the light of the previous, the researcher conducted this study for evaluating the impact of protocol of nursing intervention on sexual dysfunction among women with cervical cancer

As regards to age as of the studied sample as a part of demographic characteristics of the study subjects, the present study indicated that slightly more than half of the study sample their age more than 50 years old. This finding is supported by Ahmed\& Hassan, (2016) that studied "Application of PLISSIT Counseling Model for Women with Cervical Cancer Undergoing Treatment on Enhancing Sexuality" in Egypt found that slightly more than half of their sample their age ranged from (40-50) years with mean age $(42.11 \pm 10.02)$ years. This highlights the importance of the screening women for cervical cancer and educating them about preventive measures and guidance regarding life style modification, prevention, early detection and treatment of cervical cancer.

Similarly, to current study findings, Zhou,et al, (2017) who study " Patterns and predictors of healthcare-seeking for sexual problems among cervical cancer survivors: An exploratory study in China", found that slightly less than half of women their age ranged from(46-55) years old. 
Education has been showed to be a source of empowerment for females. Concerning to educational level of women, the results of the current study indicated that, slightly less than half of the studied women had secondary education and two thirds were house wives. This also supported by Zhou, et al, (2017) who study " Patterns and predictors of healthcare-seeking for sexual problems among cervical cancer survivors: An exploratory study in China" found that about half of the patients had education up to Junior high school level or less.

Concerning occupation of women the present study showed that slightly more than half of women were house wives this is supported by Khalil, et al.,(2015) who study the " Impact of cervical cancer on quality of life: beyond the short term (Results from a single institution)" in Iran and found that the majority of the participants were married, Arabic white, mostly illiterates and slightly less than three quarters of the cases were unemployed. This may be related to differences in culture and beliefs related to education and employment of women.

Concerning women's knowledge about cervical cancer (definition, causes, manifestations, predisposing factors, prevention, diagnosis, management ) the current study revealed that approximately two thirds of women had unsatisfactory knowledge at pre intervention, this may be related to embarrassment, lack of access to information, and low education about sex are considered the main barriers for opening sexual discussion. Also a large part of professionals in the health area are not found to be adequately prepared for the approach of sexual complaints. This can be related to the low knowledge, due to the lack of disciplines in curricular grades of graduation courses which approach human sexuality as not only limited to reproductive function.

However there was a high statistical significant improvement in the women's knowledge about cervical cancer in which approximately the majority of women had satisfactory knowledge at post intervention $\mathrm{p}(<0.001)$. This may be due to continous education and encouragement among the studied women by using the protocol of nursing intervention.

In the same line Getahun, et al, (2013) who study "Comprehensive knowledge about cervical cancer is low among women in Northwest 
Ethiopia" revealed that knowledge about cervical cancer was poor though majority of the women had heard about the disease. Specifically, the knowledge of women on risk factors, signs and symptoms was poor. Education about the disease must include information on risk factors, sign and symptoms of cervical cancer. This may be due to decrease high level of education among their studied women.

Also Mitiku, Tefera, (2016) who studied "Knowledge about Cervical Cancer and Associated Factors among 15-49 Year Old Women in Dessie Town, Northeast Ethiopia " revealed that using the sum of all knowledge items (definition, risk factors , symptoms, preventive measures, ) determined that a total of slightly more than half of the participants had sufficient knowledge about cervical cancer at post intervention. This may be due to the continous education and motivation of women by the researcher through using the educational intervention package.

Regarding to total scores of female sexual functions index(FSFI) (desire, arousal, lubrication, orgasm, satisfaction, pain) the current study findings showed that the majority of women had sexual dysfunction at pre intervention. This may be this may be related to embarrassment, lack of access to information, low education about sex and ignorance of communication about sexual concerns by the health care provider.

However, half of women had sexual functioning at post intervention and improved in items of FSFI (desire, arousal, lubrication, orgasm, satisfaction, pain). Highly statistical significant difference is observed in the total scores of FSFI among studied sample at pre and post intervention. This may be due to continous education and support among study sample about sexual conerns with cervical cancer that provided a great support and encouraging womens to decrease immparesment about talking in their sexual proplems.

This is supported by Afiyant, Nur, Milanti, (2016) who studied "Evaluating sexual nursing care intervention for reducing sexual dysfunction in Indonesian cervical cancer survivors" stated that nursing care intervention on sexuality (FSFI) were statistically significant and alleviated dyspareunia (pain) .Nursing care intervention also improved sexual satisfaction, which covered the second most improved domain. Vaginal lubrication and Sexual desire of the respondents and 
their spouses were also improved. Orgasm was also improved. This may be due to high level of education among their studied women and their parteners.

In agreement with our study result Mohamed, Ouda, Said , (2018) who studied "Effectiveness of Application of PLISSIT Counseling Model on Sexuality Among Women with Dyspareunia " in Egypt revealed that there were statistically significant differences between pre and post application of PILLIST model $(\mathrm{P}<0.001)$ as regard to elements of female sexual function index (FSFI) including desire, arousal, orgasm, satisfaction and pain. And disagree with the present study results in which there were no statistically significant differences regarding lubrication $(\mathrm{P}>0.4)$. This finding can be explained by how cancer treatment leads to vaginal mucosal damage leading to vaginal dryness and stenosis that mostly treated with application of external moistures and hormonal replacement.

This is consistent with Rostamkhani, et al. (2015) who studied " Addressing the sexual problems of Iranian women in a primary health care setting: A quasiexperimental study " reported that significant improvement was found in FSFI sub-domain scores, including sexual desire, arousal, orgasm, satisfaction ,lubrication and pain in the intervention group compared to the control group.

In congruent with the current study findings Bakker, (2016) who studied "A nurse-led sexual rehabilitation intervention after radiotherapy for gynecological cancer " During the intervention by using educational booklet about sexuality, Participants' sexual functioning significantly changed over time compared to their situation before diagnosis, participants reported lower levels of sexual functioning at 1 month However, after treatment with rehabilitation therapy (RT), participants' sexual functioning significantly increased over time. This may be due to after 1 month of treatment sexual symptomes are vigrous related to treatment side effects and women fear to engage in any sexual activity.

Regarding to women's total sexual distress scores this study revealed that majority of the studied women had sexual distress at preintervention while majority of them had no sexual distress at postintervention. Highly statistical significant difference is observed 
among women in the total scores of the sexual distress scale.

In consistent with the current study findings Hee, (2013) who study "Effect of PLISSIT Model Sexual Health Enhancement Program for Women with Gynecologic Cancer and Their Husbands " reported that post intervention results showed significant differences between the groups for sexual function, sexual distress, and marital intimacy in the women and for subjective happiness in the husbands. Results also indicate that the sexual health enhancement program is effective in improving sexual function, lowering sexual distress, increasing marital intimacy, and subjective happiness in women.

In the same line with our study findings Ali, et al., (2018) who conduct a study about "Sexual distress and sexual function in a sample of Iranian women with gynecologic cancers" in Iran found that mean score for the FSFI was 19.4.This score reflects low levels of sexual function among the patients with gynecologic cancer. The mean total score for the sexual distress was 29.2 which also indicated low levels.

In disagreement with the current study findings Bakker,
(2016) who that participants' sexual distress was not significantly different over time. Compared to their prediagnosis situation, participants reported higher levels of sexual distress at 1 month and 6 months after treatment with RT and a trend for higher levels at 12 months after rehabilitation therapy. Also, after treatment with RT, participants' levels of sexual distress did not significantly decrease over time during the intervention. This may be related to the study participants were evaluated early in the recovery phase, therefore, it should be noted that sexual distress among GCS may further recover between 12 and 24 months.

Regarding to women's total body image scores the present study indicated that the majority of women had body image distress at pre intervention. Wherease after intervention the majority of them had good body image. Highly statistical significant difference is observed among women in the total scores of the body image scale.

This findings was supported by Sewell, Edwards , (2015) who studied "Pelvic genital cancer: Body image and sexuality" reported that a treatment of gynecological cancer typically affects body parts associated 
with womanhood and femininity, causing considerable body changes that are likely to alter body image. After this treatment is completed, gynecological cancer patients are often left with the residual effects of surgery and/or various medical procedures, such as radiation and chemotherapy that may affect on sexuality and couple satisfaction.

In the same line Sook, Ran, (2014) who conduct study about "Comparison of Distress and Body Image according to the Stages of Cancer Survivorship in Gynecological Cancer Patients" found that the score of body image was significantly lower in the acute cancer survival stage than long-term cancer survival ( $\mathrm{F}=3.69, \mathrm{p}=.026)$. Gynecological cancer patients in the acute cancer survival among the three stages will to need nursing intervention to decrease distress and improve body image.

In addition to Trachtenberg, et al., (2019) who studied "Feasibility and acceptability of i-Restoring Body Image after cancer; A pilot trial for female cancer survivors " revealed that the majority of their participants experienced significant reductions in body image distress and improvements in embodiment scores.
These pre intervention and post intervention changes were statistically significant. This may be related to the addressing of sexual concerns after cancer treatment in their nursing intervention and specifically body image related distress.

Furthermore similar to the findings of El- Sayed\& Ahmed, (2015) who conducted their study in Egypt represented body image scores pre and post intervention among the studied women with breast cancer. It showed statistically significant difference between body image scale level before and after application of PLISSIT counseling model. This may be due to high level of education among their studied women.

\section{Conclusion}

The findings of this study supported the research hypotheses that, there was high statistical significant difference in the women's total score of knowledge about cervical cancer, total score of female sexual function index, total scores of female sexual distress scale and total scores of body image scale at pre and post intervention after application of educational booklet. 


\section{Recommendations}

1- Disseminate the multidisciplinary collaboration approach for addressing sexual problems related to cervical cancer

2- Preparing health classes for cervical cancer women regarding sexual dysfunction following cervical cancer.

3- Further research about nurse's perception and practices regarding sexual dysfunction with cervical cancer.

\section{References}

Afiyanti, Y., Nur, I., Milanti, A. (2016). Evaluating sexual nursing care intervention for reducing sexual dysfunction in Indonesian cervical cancer survivors, Asia pacific journal of oncology nursing, Volume: 3 Issue : 3 | Page : 266-

Ahmed, S.\& Hassan. S., (2016): Application of PLISSIT Counseling Model for Women with Cervical Cancer Undergoing Treatment on Enhancing Sexuality, American Journal of Nursing Science 5(3): 85-95

American Cancer Society, (2020). Treatment Options for Cervical Cancer, by Stage

Araujo,F., Janaina,L., Laurentino,S. ,Vieira,C.,(2016): Quality of life and sexual function after cervical cancer: a cross-sectional study, online Brazilian Journal of Nursing, vol. 15, 2016, pp. 542-545

Ali, M., Bahramia, N., Yaghoobzadehb, A., Parker, A., Huak, Y.,(2018): Sexual distress and sexual function in a sample of Iranian women with gynecologic cancers, European Journal of Oncology Nursing, 35 , 47-53

Bakker, R., Mens, J ., Groot, H., Tuijnman, C., Braat, C., Hompus, W., Poelman, J., Laman, M., Velema, L., Kroon, C., Doorn, H., Creutzberg, C., ter, M.,(2016): A nurse-led sexual rehabilitation intervention after radiotherapy for gynecological cancer El- Sayed, N., Ahmed, M., (2015): Effectiveness of Application of PLISSIT Counseling Model on Sexuality for Breast Cancer's Women Undergoing Treatment, American Journal of Nursing Science 4(4): 218230

Getahun, F., Mazengia, F., Abuhay, M., Birhanu Z., (2013): Comprehensive knowledge about cervical cancer is low among women in Northwest Ethiopia. BMC Cancer 13, 2,

Hee, J., (2013): Effect of PLISSIT Model Sexual Health Enhancement Program for Women with Gynecologic Cancer and Their Husbands, Journal of Korean Academy of Nursing. 2013, 
Vol. 43 Issue 5, p681-689. 9p. 1 Diagram, 4 Charts

Boyle, P., Levin, B., (2014): World Cancer Report 2008. IARC Cancer Treatment: cancer/news/new-screeningguidelines-for cervical- cancer. How Can Psychologists Help? Prof Psychol Res. 41 (6): 533-540, e

Brunault, P., Champagne, A.L., Huguet, G., Suzanne, I., Senon, J.L., Body, G., Rusch, E., Magnin, G., Voyer, M., Réveillère, C., (2016). Major depressive disorder, personality disorders, and coping strategies are independent risk factors for lower quality of life in non-metastatic breast cancer patients, Psycho-Oncology, Wiley, 25 (5), pp.513-520

Cândido,J., Mucha,R., Bhadra,D., Tavares,M., Carlos,L.,(2017). Early Age at First Sexual Intercourse is Associated with Higher Prevalence of High-grade Squamous Intraepithelial Lesions (HSIL)

Conrad, M.\& Shiel, W.,(2018). Pap Smear,

Chow, KM., Chan, JC. Cho, i ,K., Chan CW.,(2016): A review of psych educational interventions to improve sexual functioning, quality of life, and psychological outcomes inEthiopia gynecological cancer patients. Cancer Nurs. 39(1):20-3.
Hofsjö, A., Bergmark , K., Blomgren ,B., Jahren , H., Bohm , N., (2017). Radiotherapy for cervical cancer - impact on the vaginal epithelium and sexual function

Habtu,Y., Yohannes,S., Laelago,T. (2017). Knowledge, attitude and practice for cervical cancer prevention and control among women of childbearing age in Hossana Town, Hadiya zone, Southern Ethiopia: Community-based cross-sectional study

ICO/IARC Information Centre on HPV and Cancer,(2018). Egypt Human Papillomavirus and Related Cancers, Fact Sheet 2018 (2018-12-10)

Khalil, J., Bellefqih, S., Sahli, N., Afif, M., Elkacemi, H., Elmajjaoui, S., Kebdani, T and Benjaafar, N. (2016). Impact of cervical cancer on quality of life: beyond the short term (Results from a single institution) Gynecologic Oncology Research and Practice (2015) 2:7

Mitiku, I., Tefera, F. (2016). Knowledge about Cervical Cancer and Associated Factors among 15-49 Year , Old Women in Dessie Town, Northeast Mohamed, A., Ouda ,S., Said ,S.,(2018). Effectiveness of Application of PLISSIT Counseling Model on Sexuality Among Women with 
Dyspareunia. American Journal of Nursing Science. Vol. 7, No. 2, 2018, pp. 73-83,

Martin, L.,( 2018). Cervical cancer, Cervical cancer overview

Rostamkhani, F., Jafari, F, Ozgoli, G., and Shakeri, M (2015). Addressing the sexual problems of Iranian women in a primary health care setting: A quasiexperimental study, Iranian Journal of Nursing and Midwifery Research | January-February 2015 | Vol. 20 | Issue 1, 139-146,

Soleimani, MA., Bahrami, N., Yaghoobzadeh, A., Parker, A., Chan, YH. (2018). Sexual distress and sexual function in a sample of Iranian women with gynecologic cancers, European Journal of Oncology Nursing, Volume 35, Pages 47- 53,

Sook,J., Ran,H.,(2014). Comparison of Distress and Body Image according to the Stages of Cancer Survivorship in Gynecological Cancer Patients, Asian Oncology Nursing, Vol. 14 Issue 1, p1522. $8 \mathrm{p}$,

Sewell H. H. • Edwards D. W. (2015). Pelvic Genital Cancer: Body Image and Sexuality,

Trachtenberg, L., Wong, J., Rennie, H., McLeod, D., Leung, Y., Warner, E., Jane, M.,(2019). Feasibility and acceptability of i-Restoring Body Image after Cancer (i-ReBIC): A pilot trial for female cancer survivors, PsychoOncology journal, volume 29, issue 8,

WHO, (2018): Human papillomavirus (HPV) and cervical cancer

Zhou ,L., Qing,L., Shen ,B., Jin ,Z., Liu ,H., Chen ,Y.,(2017). Patterns and predictors of healthcare-seeking for sexual problems among cervical cancer survivors: An exploratory study in China, Biomed Research journal- India, Volume 28, Issue14, available at; 14, 


\section{أثر بروتوكول تلخل تمريضي على العجز الجنسي لاى النساء المصابات بسرطان عنق الرحم هاجر كمال مسعود- رجاء علي تحمد- سعاد عبد السلام رمضان- حنان الزبلاوي حسن}

يؤثر سرطان عنق الرحم على جميع جوانب حياة المريض ، بما في ذلك الأداء الجنسي والعلاقة الحميمة. لذلك هدفت الدراسة الحالية إلى تقييم أثر بروتوكول التدخل التمريضي على العجز الجنسي لدى النساء المصابات بسرطان عنق الرحم. تم إجر اء تصميم در اسة التدخل في العيادة الخارجية في وحدة الأورام بمستشفى بني سويف الجامعي علي • V امر أة في الدر اسة. وكثفت النتائج ان هناك فروق ذات دلالة إحصائية عالية في الدرجة الكلية لمعلومات النساء بسرطان عنق الرحم ، وإجمالي درجات مؤشر الوظيفة الجنسية للإناث ، ومقياس الضيق الجنسي للإناث ، ومقياس صورة الجسم عند التذخل اللاحق حيث حصلت النساء على درجة أعلى في مرحلة ما بعد التدخل ـ و واوصت الدر اسة الحالية بنهج تعاون متعدد التخصصات لمعالجة المشاكل الجنسية المتعلقة بسرطان عنق الرحم ، و إعداد فصول صحية للنساء المصابات بسرطان عنق الرحم فيما يتعلق بالضعف الجنسي مع سرطان عنق الرحم وإجر اء مزيد من البحوث حول تصور الممرضة وممارساتها فيما يتعلق بالعجز الجنسي مع سرطان عنق الرحم. 